Barlow's disease. Ann Thorac Surg. 2006;82: 2096-100.

2. Braunberger E, Deloche A, Berrebi A, Abdallah F, Celestin JA, Meimoun P, et al. Very long-term results (more than 20 years) of valve repair with Carpentier's techniques in nonrheumatic mitral valve insufficiency. Circulation. 2001;104(12 Suppl 1):I8-11.

3. Adams DH, Kadner A, Chen RH. Artificial mitral valve chordae replacement made simple. Ann Thorac Surg. 2001;71:1377-8. doi:10.1016/j.jtcvs.2007.09.028

\section{Ascending aortic cannulation in acute type $A$ aortic dissection: Is intraoperative brachiocephalic malperfusion a possibility? \\ To the Editor:}

I read with great interest the recent article by Dr Jakob and colleagues ${ }^{1}$ detailing their pilot experience with direct cannulation of the ascending aorta in acute type A dissection $(\mathrm{n}=8: 5$ with preoperative cerebral malperfusion). Their method entailed primary venous exsanguination, cannulation of ascending aortic true lumen under direct vision, controlled deairing, followed by standard cardiopulmonary bypass after proximal aortic clamping.

The clinical consideration here is whether this cannulation technique protects against brachiocephalic malperfusion, given that 5 of 8 patients presented with brachiocephalic dissection and cerebral malperfusion in the setting of true lumen pulsatile perfusion.

The following questions relate to this consideration:

1. What intraoperative monitoring was used to detect brachiocephalic malperfusion?

2. Were any episodes of brachiocephalic malperfusion detected intraoperatively? If so, how were they managed?

3. Was surgical intimal fenestration above the ascending aortic clamp ever required to restore adequate brachiocephalic perfusion? In our practice, this management technique has been used successfully to correct innominate malperfusion detected intraoperatively by transcutaneous scanning of the right carotid artery. $^{2}$

4. Was epiaortic ultrasound guidance for cannulation of the dissected ascending aorta ever considered? This imaging technique has been used successfully in this scenario. ${ }^{3}$ It can also confirm correct placement of the arterial cannula.

I congratulate the authors again on a fine study. I look forward to their feedback about these intraoperative considerations.

John G.T. Augoustides, MD, FASE Department of Anesthesiology and Critical Care Hospital of the University of Pennsylvania Philadelphia, $\mathrm{Pa}$

Financial support provided by the Department of Anesthesiology and Critical Care, Hospital of the University of Pennsylvania

\section{References}

1. Jakob H, Tsagakis K, Szabo A, Wiese I, Thielmann M, Herold U. Rapid and safe direct cannulation of the true lumen of the ascending aorta in acute type A aortic dissection. J Thorac Cardiovasc Surg. 2007;134:244-5.

2. Augoustides JGT, Kohl BA, Harris H, Pochettino A. Color-flow Doppler recognition of intraoperative brachiocephalic malperfusion during operative repair of acute type A aortic dissection: utility of transcutaneous carotid artery ultrasound scanning. J Cardiohorac Vasc Anesth. 2007;21:81-4.

3. Inoue Y, Ueda T, Taguchi S, Kashima I, Koizumi K, Takahashi R, et al. Ascending aorta cannulation in acute type A aortic dissection. Eur J Cardiothorac Surg. 2007;31:976-9. doi:10.1016/j.jtcvs.2007.07.069

\section{Reply to the Editor:}

We appreciate Dr Augoustides' important and meaningful questions regarding brachiocephalic dissection and cerebral malperfusion in the surgical treatment of patients with acute type A aortic dissection.

To provide specific answers, we follow his questions as raised after specifying the baseline situation in our 8 patients: All patients came in with a computed tomographic scan diagnosis obtained elsewhere. Six patients demonstrated dissection of the brachiocephalic trunk, 2 of them hemodynamically in highly unstable condition with tamponade. In 2 patients, no dissection of the truncus was seen, but severe instability and cardiac tamponade was observed in 1 patient. Five patients had clinical signs of cerebral malperfusion, and 1 patient was found unconscious and was intubated before arrival. Thus, brachiocephalic malperfusion was present before surgery in at least 5 pa- tients, confirmed in all by computed tomographic scan.

1. Intraoperative monitoring to detect brachiocephalic malperfusion consisted of bilateral monitoring of radial artery pressure in all but 1 of the highly unstable patients, forcing immediate surgery. To date, no transcranial Doppler or transcutaneous scanning of the carotid arteries has been used.

2. No intraoperative episodes of new brachiocephalic malperfusion were detected. Validation of this simplistic statement can be given in part by the open approach we used: After exsanguination and opening of the ascending aorta, including the retracted intimal sac, the aortic arch could be inspected directly with both head vessels exposed for some seconds. By placement of the aortic cannula in the mid arch position within the true lumen under direct vision and controlled deairing followed by clamping of the ascending aorta adjacent to the cannula, we were able to immediately exclude the primary tear in the ascending aorta, including the blown up false lumen, which primarily caused the obstruction of the brachiocephalic trunk.

Distal repair was performed after the target temperature had been reached and after a short period of circulatory arrest and selected cannulation of the brachiocephalic trunk. Backflow via the left carotid artery gave additional information of patency of the right carotid artery. The left carotid artery was cannulated immediately thereafter.

3. The aforementioned surgical strategy of immediate exclusion of the primary aortic tear, including the blown up false lumen, obviated any intimal fenestration above the aortic clamp, even in the presence of a re-entry site in the aortic arch. In the 7 patients with bilateral radial artery pressure monitoring, identical pressures were seen throughout cooling.

4. Occasional dismal experience has been incurred with "blind" direct ascending aortic cannulation in emergency situations, with thrombotic material from the false lumen being 
dispersed, especially in patients with ongoing dissection beyond 24 hours. We are therefore concerned that even placement of the cannula into the true lumen under epiaortic scanning could result in the same dilemma of potentially dispersing thrombi via the wide open connection to the false lumen in the ascending aorta. ${ }^{1}$ Thus, we do believe that our new approach might be a safer way toward adequate antegrade perfusion of the cerebrum during the cooling phase.

Heinz Jakob, $M D^{a}$ Eva Assenmacher, $M D^{b}$ Konstantinos Tsagakis, $M D^{a}$ Ulf Herold, $M D^{a}$

Department of Thoracic and Cardiovascular Surgery ${ }^{a}$ Department of Anesthesiology ${ }^{b}$ West German Heart Center Essen University Hospital Essen Essen, Germany

\section{Reference}

1. Inoue $\mathrm{Y}$, Ueda $\mathrm{T}$, Taguchi $\mathrm{S}$, Kashima $\mathrm{I}$, Koizumi K, Takahashi R, et al. Ascending aorta cannulation in acute type A aortic dissection. Eur J Cardiothorac Surg. 2007;31: 976-9.

doi:10.1016/j.jtcvs.2007.10.007

\section{Better surgical prognosis for patients with Down Syndrome:} To the Editor:

In a recent issue, we read the interesting paper by Seifert et al. on risk of death during hospitalization for pediatric cardiac sur- gery. ${ }^{1}$ In their multicentric study, the authors unequivocally demonstrated that Down syndrome is associated with a significant lower mortality after cardiac surgery for congenital heart defects, affirming that "the effect of Down syndrome on immediate outcome is not clear.",

Although previous studies have suggested that patients with this syndrome have an increased risk of mortality after repair of ventricular septal defect or atrioventricular canal, ${ }^{1}$ recent papers have shown that the presence of Down syndrome did not increase the surgical mortality in children with ventricular septal defect ${ }^{2}$ or with tetralogy of Fallot. ${ }^{3}$ Moreover, in patients with partial ${ }^{4}$ and complete ${ }^{5}$ atrioventricular canal (very frequent heart defects in children with trisomy 21), the Down syndrome is associated with significantly lower mortality and morbidity after cardiac surgery.

These surgical results are probably due to the peculiar anatomic cardiac pattern of patients with atrioventricular canal and Down syndrome, including a lower prevalence of left-sided obstructions, right ventricular dominance, and additional anomalies of the mitral valve. ${ }^{6}$ We can suggest that the effect of best results on children with atrioventricular canal $^{4,5}$ could influence all surgical results in patients with Down syndrome. ${ }^{1}$

In conclusion, in spite of the tendency to infections and early pulmonary hypertension in children with Down syndrome, cardiac surgery not only is not contraindicated, as previously suggested, but can be performed with very good results, as clearly shown by Seifert et al. ${ }^{1}$

Claudia Saffirio, $M D^{a}$ Bruno Marino, $M D^{a}$

\author{
Roberto Formigari, $M D^{b}$ \\ Pediatric Cardiology ${ }^{a}$ \\ Department of Pediatrics \\ University of Rome "La Sapienza" \\ Rome, Italy \\ Pediatric Cardiology and Cardiac Surgery ${ }^{b}$ \\ Policlinico "S.Orsola-Malpighi" \\ Bologna, Italy
}

\section{References}

1. Seifert HA, Howard DL, Silbert JH, Jobes DR. Female gender increases the risk of death during hospitalization for pediatric cardiac surgery. J Thorac Cardiovasc Surg. 2007; 133:668-75

2. Knott-Craig CJ, Elkins RC, Ramakrishnan K, Hartnett DA, Lane MM, Overholt ED, et al. Associated atrial septal defects increase perioperative morbidity after ventricular septal defect repair in infancy. Ann Thorac Surg. 1995; 59:573-8.

3. Michielon G, Marino B, Formigari R, Gargiulo G, Picchio F, Digilio MC, et al. Genetic syndromes and outcome after surgical correction of tetralogy of Fallot. Ann Thorac Surg. 2006;81:968-75.

4. Giamberti A, Marino B, di Carlo D, Iorio FS, Formigari R, de Zorzi A, et al. Partial atrioventricular canal with congestive heart failure in the first year of life: surgical options. Ann Thorac Surg. 1996;62:151-4.

5. Formigari R, Di Donato RM, Gargiulo G, Di Carlo D, Feltri C, Picchio FM, et al. Better surgical prognosis for patients with complete atrioventricular septal defect and Down's syndrome. Ann Thorac Surg. 2004;78:666-72; discussion 672. Review.

6. De Biase L, Di Ciommo V, Ballerini L, Bevilacqua M, Marcelletti C, Marino B. Prevalence of left-sided obstructive lesions in patients with atrioventricular canal without Down's syndrome. $J$ Thorac Cardiovasc Surg. 1986;91:467-9.

doi:10.1016/j.jtcvs.2007.07.065 